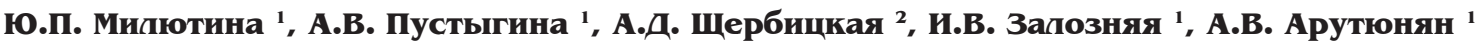 \\ СРАВНЕНИЕ ПОКАЗАТЕЛЕЙ ОКИСЛИТЕЛЬНОГО СТРЕССА В СЫВОРОТКЕ КРОВИ КРЫС ПРИ РАЗЛИЧНЫХ МОДЕЛЯХ ГИПЕРГОМОЦИСТЕИНЕМИИ
}

\author{
1 ФГБНУ «Научно-исследовательский институт акушерства, гинекологии и репродуктологии \\ имени Д.О. Отта", Санкт-Петербург, Россия \\ ${ }^{2}$ ФГБУН Институт эволюционной физиологии и биохимии им. И.М. Сеченова РАН, Санкт-Петербург,

Целью работы стало сравнение степени окислительных повреждений макромолекул, а также оценка состояния антиоксидантной системы при хронически повышенном содержании гомоцистеина в плазме крови у взрослых животных и у крысят, пренатальное развитие которых протекало в условиях гипергомоцистеинемии (ГГЦ). При воздействии ГГЦ на взрослых животных так же, как и в отдаленном периоде, после пренатальной ГГЦ происходит повышенное образование нитротирозина, а также изменение активности супероксоддисмутазы.

Ключевые слова: гипергомоцистеинемия, окислительный стресс, супероксиддисмутаза

\section{THE COMPARISON OF OXIDATIVE STRESS PROFILES IN RAT BLOOD SERUM IN DIFFERENT EXPERIMENTAL MODELS OF HYPERHOMOCYSTEINEMIA}

\author{
Y.P. Milyutina ', A.V. Pustygina ', A.D. Spcherbitskaya ${ }^{2}$, I.V. Zaloznyaya ', A.V. Arutyunyan ${ }^{1}$ \\ ${ }^{1}$ Research Institute of Obstetrics, Gynecology, and Reproductology named after D.O. Ott, Saint \\ Petersburg, Russia \\ ${ }^{2}$ Sechenov Institute of Evolutionary Physiology and Biochemistry RAS, Saint Petersburg, Russia
}

It is well known that much pathology observed immediately after birth or in later periods of postnatal life is associated with adverse prenatal development. The mechanisms of this phenomenon, however, warrant further investigation. Accordingly, the aim of the present study was to compare oxidative damage caused to macromolecules, especially proteins and nucleic acids, and to assess the state of the antioxidant system in rats with chronically elevated blood plasma L-homocysteine (Hcy), as well as in their offsprings exposed to hyperhomocysteinemia (HHcy) throughout pregnancy. It was shown that blood Hcy was elevated in both studied models, but in the rats with past HHcy, it returned back to normal values in two months of postnatal life. Both alimentary and prenatal HHcy increased nitrotyrosine production and changed the activity of superoxide dismutase in the experimental animals and their matured offspring. The high activity of the enzyme in late periods found in animals that underwent prenatal HHcy gave indirect evidence to hypergeneration of superoxide radical. Despite the restored level of Hcy, free radical oxidation activation was observed in the rats, whose mothers had been administered with L-methionine throughout pregnancy, which was confirmed by elevated blood serum nitrotyrosine. The data obtained were concordant with the idea that the elevated blood plasma Hcy found in pregnant rats resulted in oxidative stress developed in their offsprings, which manifested itself months later on their postnatal life.

Key words: hyperhomocysteinemia, oxidative stress, superoxide dismutase

\section{ВВЕДЕНИЕ}

В настоящее время признано, что одним из механизмов, посредством которых реализуется токсический эффект гомоцистеина (ГЦ), является его способность генерировать активные формы кислорода (АФК). ГЦ имеет активную тиоловую группу, легко окисляется в присутствии кислорода и ионов металлов с переходной валентностью с формированием дисульфидов и активных кислородных радикалов - супероксидного анион-радикала и других АФК, таких как перекись водорода и гидроксильный радикал [7]. Кроме того, повышенный уровень ГЦ может косвенно приводить к развитию окислительного стресса (OC) путем подавления транскрипции, трансляции и каталитической активности таких антиоксидантных ферментов, как супероксиддисмутаза (СОД) и глутатионпероксидаза [12]. Отмечено также, что снижение уровня NO при высоком уровне ГЦ является результатом либо снижения доступности NO в результате образования пероксинитрита, либо изменения активности
NO-синтазы [14]. Показано, что концентрация ГЦ в материнской крови определяет его содержание в плазме плода, отмечена положительная корреляция между ними [6]. Установлено, что ГЦ, как и метионин, беспрепятственно проникает через фетоплацентарный барьер в кровяное русло плода [11]. Однако результаты воздействия гипергомоцистеинемии (ГГЦ) на взрослый организм и развивающийся плод существенно различаются. Повышение концентрации ГЦ в крови у взрослых животных приводит к тому, что большинство своих токсических эффектов он реализует непосредственно в сосудах, влияя на клетки эндотелия, пролиферацию гладкомышечных клеток сосуда и форменные элементы крови [2]. При этом ГГЦ является одной из причин таких тяжелейших врожденных патологий плода, как пороки сердца, анэнцефалия, незаращение спинномозгового канала. Высокая уязвимость растущего мозга эмбриона/ плода к действию свободных радикалов объясняется достаточно высокими показателями концентрации ионов железа и интенсивности его поступления 
в мозг в этот период, а также слабо развитой, по сравнению со взрослым мозгом, антиоксидантной системой (AOC) $[4,13]$. Необходимо отметить недостаточность и противоречивость экспериментальных данных об особенностях свободнорадикальных процессов в регуляции развития различных систем организма, в частности ЦНС, в эмбриональный период как в норме, так и при различных воздействиях, сопровождающихся дополнительным образованием АФК и/или изменением работы отдельных звеньев AOC. Показана статистически значимая причинная связь многих патологических состояний, наблюдающихся сразу после рождения и в более поздних периодах постнатальной жизни с неблагополучием внутриутробного развития. Однако механизмы этого явления требуют дальнейшего изучения. В этой связи целью работы явилось сравнение степени окислительных повреждений макромолекул, особенно белков и нуклеиновых кислот, а также оценка состояния AOC при хронически повышенном содержании ГЦ в плазме крови у взрослых животных и у крысят, пренатальное развитие которых протекало в условиях ГГЦ.

\section{МАТЕРИАЛЫ И МЕТОДЫ}

Эксперименты были выполнены на половозрелых крысах-самках линии Wistar массой 150-200 г. Животные содержались в виварии с искусственной вентиляцией и контролируемым стандартным световым режимом (12 часов света - 12 часов темноты), получали стандартный корм и воду. Животные были разделены на следующие группы:

Группа 1 - половозрелые самки крыс, которым ежедневно в течение 30 дней перорально через зонд вводили либо воду (контрольная подгруппа 1), либо метионин в концентрации 0,6 мг/кг массы животного (опытная подгруппа 1).

Группа 2 - половозрелые самки, матери которых в период беременности от зачатия до родов находились на ежедневном пероральном потреблении либо воды (контрольная подгруппа 2), либо метионина в концентрации 0,6 мг/кг массы животного (опытная подгруппа 2).

Для подтверждения развития экспериментальной ГГЦ в плазме крови определяли содержание ГЦ иммуноферментным методом с использованием тест-системы Axis Shield (Великобритания). Развитие пренатальной ГГЦ фиксировали по уровню ГЦ в крови новорожденных крысят. О степени развития ОС судили по содержанию продуктов окислительной модификации макромолекул. Содержание 8-гидрокси-2'-деоксигуанозина ( 80 НдГ), биомаркера окислительного повреждения ДНК, в сыворотке крови определяли ИФА методом с использованием тест-системы DNA Damage Enzo Life Sciences (США). Для оценки окислительной модификации белков нами определялось содержание 3-нитротирозина (тест-система Hycult Biotech (Нидерланды)). Состояние АОС оценивали по концентрации аскорбиновой кислоты (Immunodiagnostik, Германия) и активности супероксиддисмутазы (СОД) в сыворотке крови с помощью тест-системы фирмы Cayman
Chemical Company (США). Все работы с лабораторными животными выполнялись в соответствии с положениями Хельсинкской декларации Всемирной медицинской ассоциации о гуманном отношении к животным (2000 г. ред.), принципами гуманности, изложенными в директиве Европейского союза № 86/609 EC.

Статистическая обработка полученных данных проведена с использованием программы Statistica 10.0. На основании оценки нормальности распределения признаков (W-критерий Шапиро - Уилка) для сравнения двух независимых выборок был применен параметрический t-критерий. Различия считались статистически значимыми при $p<0,05$. Данные представлены в процентах от значений соответствующих контрольных групп.

\section{РЕЗУЛЬТАТЫ И ОБСУЖДЕНИЕ}

У новорожденных крысят, матери которых принудительно в течение всей беременности получали метионин, уровень содержания ГЦ был значимо выше $(16,1 \pm 3,97$ мкM), чем у крысят контрольной группы $(6,2 \pm 0,77$ мкM). Значимых различий в уровне ГЦ между крысами в возрасте 2 месяцев в контрольной группе $(9,5 \pm 0,57$ мкМ) и в группе, перенесшей пренатальную ГГЦ (10,3 £ 0,69 мкМ), обнаружено не было. При хронической метиониновой нагрузке половозрелых крыс у них развивается состояние ГГЦ, при котором уровень ГЦу подопытных животных значимо $(p<0,001)$ выше $(19,7 \pm 4,07$ мкМ), по сравнению с таковым у контрольных животных (6,3 \pm 0,30 мкМ).

В сыворотке крови самок крыс, подвергшихся ГГЦ во взрослом состоянии, было выявлено значимое повышение содержания 80НдГ ( $p<0,01)$, при этом у животных, перенесших пренатальную ГГЦ, его уровень не отличался от значений контрольных

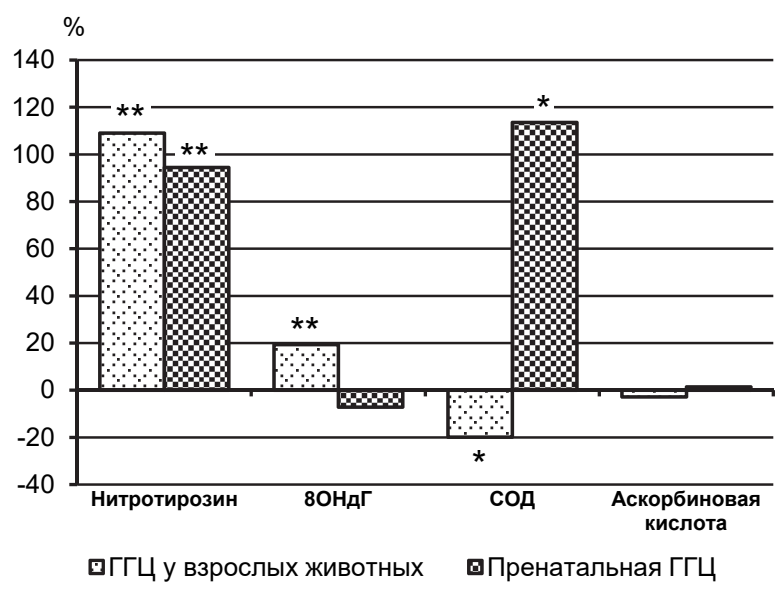

Рис. 1. Влияние различных моделей ГГЦ на показатели окислительного стресса в сыворотке крови относительно соответствующих показателей контроля (за нулевую линию принято значение показателей в группах животных без метиониновой нагрузки, получавших воду): различия содержания исследуемых показателей в группе животных, которые перенесли ГГЦ, от группы животных без метиониновой нагрузки, получавших только воду, статистически значимы при * $-p<0,05 ;{ }^{* *}-p<0,01$. 
животных (рис. 1). Установлено, что в обеих моделях ГГЦ наблюдалось значительное, примерно в 2 раза, по сравнению с контрольными животными, повышение уровня нитротирозина в сыворотке крови $(p<0,01)$. Кроме того, отмечено, что активность СОД в исследованных группах имеет разнонаправленные изменения: так, в группе животных, перенесших ГГЦ в период внутриутробного развития, в отдаленном периоде происходит статистически значимое повышение активности фермента $(p<0,05)$, тогда как 30-дневная метиониновая нагрузка половозрелых взрослых животных приводит к статистически значимому ее снижению на $20 \%(p<0,05)$.

Учитывая центральную роль супероксидного радикала, повышенное образование которого отмечено при ГГЦ, в окислительных повреждениях при патологии [14], можно ожидать изменения в активности СОД - ключевого антиоксидантного фермента. Дисмутация супероксид-аниона способствует ингибированию индуцируемого ОС высвобождения цитохрома с, блокирует активацию каспаз и, следовательно, запуск апоптоза [1]. Ранее в наших исследованиях было показано, что одним из наиболее значимых изменений в мозге новорожденных крысят после пренатальной ГГЦ, а также в гипоталамусе животных, перенесших ГГЦ, во взрослом состоянии является статистически значимое снижение активности СОД [8]. Интерпретация результатов по изменению активности ферментов у новорожденных крысят достаточно затруднительна, так как имеются различные противоречивые данные о заметных изменениях активности антиоксидантных ферментов, в частности СОД, сразу после рождения $[5,10]$, что, как полагают, связано, с резким увеличением концентрации кислорода в тканях [9]. Полученные данные по снижению активности СОД при хронической ГГЦ у взрослых животных могут быть связаны с инактивацией фермента вследствие повышенного образования пероксинитрита [3]. Высокая активность СОД, отмеченная в отдаленном периоде у животных, перенесших пренатальную ГГЦ, косвенно свидетельствует об интенсивной генерации супероксидного аниона. Несмотря на восстановившейся уровень ГЦ, у крыс, матери которых во время беременности принимали метионин, отмечена активация свободнорадикальных процессов, что подтверждается повышенным уровнем нитротирозина в сыворотке крови. Баланс между продукцией АФК и состоянием отдельных звеньев АОС имеет особое значение в период внутриутробного развития. Его нарушение может приводить к риску возникновения структурных и функциональных нарушений у потомства в постнатальном периоде развития. Результаты проведенных нами исследований согласуются с представлениями о том, что повышенное содержание ГЦ во время беременности приводит к развитию ОС у потомства, который наблюдается у них спустя месяцы постнатальной жизни.

Исследование поддержано РФФИ (грант № 1404-00746).

\section{ЛИТЕРАТУРА REFERENCES}

1. Fujimura M, Morita-Fujimura Y, Noshita N, Sugawara T, Kawase M, Chan PH (2000). The cytosolic antioxidant copper/zinc-superoxide dismutase prevents the early release of mitochondrial cytochrome $\mathrm{c}$ in ischemic brain after transient focal cerebral ischemia in mice. $J$. Neurosci., 20 (8), 2817-2824.

2. Ganguly P, Alam SF (2015). Role of homocysteine in the development of cardiovascular disease. Nutr. J., 14 (6), doi: 10.1186/1475-2891-14-6.

3. Hooijmans CR, Blom HJ, Oppenraaij-Emmerzaal D, Ritskes-Hoitinga M, Kiliaan AJ (2009). S-adenosylmethionine and S-adenosylhomocysteine levels in the aging brain of APP/PS1 Alzheimer mice. Neurol. Sci., 30 (5), 439-445.

4. Koz ST, Gouwy NT, Demir N, Nedzvetsky VS, Etem E, Baydas G (2010). Effects of maternal hyperhomocysteinemia induced by methionine intake on oxidative stress and apoptosis in pup rat brain. Int. J. Dev. Neurosci., 28 (4), 325-329.

5. Kulkarni-Narla A, Getchell TV, Getchell ML (1997). Differential expression of manganese and copper-zinc superoxide dismutases in the olfactory and vomeronasal receptor neurons of rats during ontogeny. J. Comp. Neurol., 381 (1), 31-40.

6. Murphy MM, Scott JM, Arija V (2004). Maternal homocysteine before conception and throughout pregnancy predicts fetal homocysteine and birth weight. Clin. Chem., (50), 1406-1412.

7. Perna AF, Ingrosso D, Lombardi C, Acanfora F, Satta E, Cesare CM, Violetti E, Romano MM, De Santo NG (2003). Possible mechanisms of homocysteine toxicity. Kidney Int. Suppl., (84), S137-S140

8. Pustygina AV, Milyutina YP, Zaloznyaya IV, Arutyunyan AV (2015). Indices of oxidative stress in the brain of newborn rats subjected to prenatal hyperhomocysteinemia. Neurochem. J., 9 (1), 60-65.

9. Shim SY, Kim HS (2013). Oxidative stress and the antioxidant enzyme system in the developing brain. Korean J. Pediatr., 56 (3), 107-111.

10. Shivakumar BR, Anandatheerthavarada HK, Ravindranath V (1991). Free radical scavenging systems in developing rat brain. Int. J. Dev. Neurosci., 9 (2), 181-185.

11. Tsitsiou E, Sibley CP, D’Souza SW, Catanescu O, Jacobsen DW, Glazier JD (2011). Homocysteine is transported by the microvillous plasma membrane of human placenta. J. Inherit. Metab. Dis., 34 (1), 57-65.

12. Upchurch GR Jr., Welch GN, Fabian AJ, Freedman JE, Johnson JL, Keaney JF Jr., Loscalzo J (1997). Homocyst(e)ine decreases bioavailable nitric oxide by a mechanism involving glutathione peroxidase. J. Biol. Chem., (272), 17012-17017.

13. Wells PG, Winn LM (1996). Biochemical toxicology of chemical teratogenesis. Crit. Rev. Biochem. Mol. Biol., 31 (1), 1-40.

14. Zhang X, Li H, Jin H, Ebin Z, Brodsky S, Goligorsky MS (2000). Effects of homocysteine on endothelial nitric oxide production. Am. J. Physiol. Renal Physiol., (279), 671-678. 
Сведения об авторах

Information about the authors

Милютина Юлия Павловна - кандидат биологических наук, старший научный сотрудник лаборатории межклеточных взаимодействий ФГБНУ «Научно-исследовательский институт акушерства, гинекологии и репродуктологии имени Д.О. Отта» (199034, г. Санкт-Петербург, Менделеевская линия, д. 3, тел. 8 (812) 325-32-20; e-mail: milyutina1010@mail.ru)

Milyutina Yuliya Pavlovna - Candidate of Biological Sciences, Senior Research Officer of the Laboratory of Cell-Cell Cooperation of Research Institute of Obstetrics, Gynecology, and Reproductology named after D.O. Ott (199034, Saint Petersburg, Mendeleyevskaya Line, 3; tel.: +7 (812) 325-32-20; e-mail: milyutina1010@mail.ru)

Пустыгина Антонина Васильевна - научный сотрудник лаборатории межклеточных взаимодействий ФГБНУ «Научноисследовательский институт акушерства, гинекологии и репродуктологии имени Д.О. Oтта» (e-mail: apustygina@ramler.ru) Pustygina Antonina Vasilyevna - Research Officer of the Laboratory of Cell-Cell Cooperation of Research Institute of Obstetrics, Gynecology, and Reproductology named after D.O. Ott (e-mail: apustygina@ramler.ru)

Щербицкая Анастасия Дмитриевна - младший научный сотрудник лаборатории сравнительной физиологии и патологии центральной нервной системы ФГБУН Институт эволюционной физиологии и биохимии им. И.М. Сеченова РАН (194223, г. Санкт-Петербург, пр. Тореза, 4; тел.: 8 (812) 552-79-01; e-mail: nastusiq@gmail.com)

Shcherbitskaya Anastasiya Dmitrievna - Junior Research Officer of the Laboratory of Comparative Physiology and Pathology of Central Nervous System of Sechenov Institute of Evolutionary Physiology and Biochemistry RAS (194223, Saint Petersburg, Torez av., 44; tel.: +7 (812) 552-79-01; e-mail: nastusiq@gmail.com)

Залозняя Ирина Владимировна - лаборант лаборатории межклеточных взаимодействий ФГБНУ «Научно-исследовательский институт акушерства, гинекологии и репродуктологии имени Д.О. Отта» (e-mail: irinabiolog@ramler.ru)

Zaloznyaya Irina Vladimirovna - Assistant of the Laboratory of Cell-Cell Cooperation of Research Institute of Obstetrics, Gynecology, and Reproductology named after D.O. Ott (e-mail: irinabiolog@ramler.ru)

Арутюнян Александр Вартанович - доктор биологических наук, профессор, ведущий научный сотрудник лаборатории межклеточных взаимодействий. ФГБНУ «Научно-исследовательский институт акушерства, гинекологии и репродуктологии имени Д.О. Отта», заведующий лабораторией биохимии Санкт-Петербургского института биорегуляции и геронтологии С3О РАМН (197110, г. Санкт-Петербург, пр. Динамо, 3; e-mail: alexarutiunjan@gmail.com)

Arutyunyan Aleksandr Vartanovich - Doctor of Biological Sciences, Professor, Leading Research Officer of the Laboratory of Cell-Cell Cooperation of Research Institute of Obstetrics, Gynecology, and Reproductology named after D.O. Ott, Head of the Department of Biochemistry of Saint Petersburg Institute of Bioregulation and Gerontology NWB RAMS (197110, Saint Petersburg, Dynamo av. 3; e-mail: alexarutiunjan@gmail.com) 